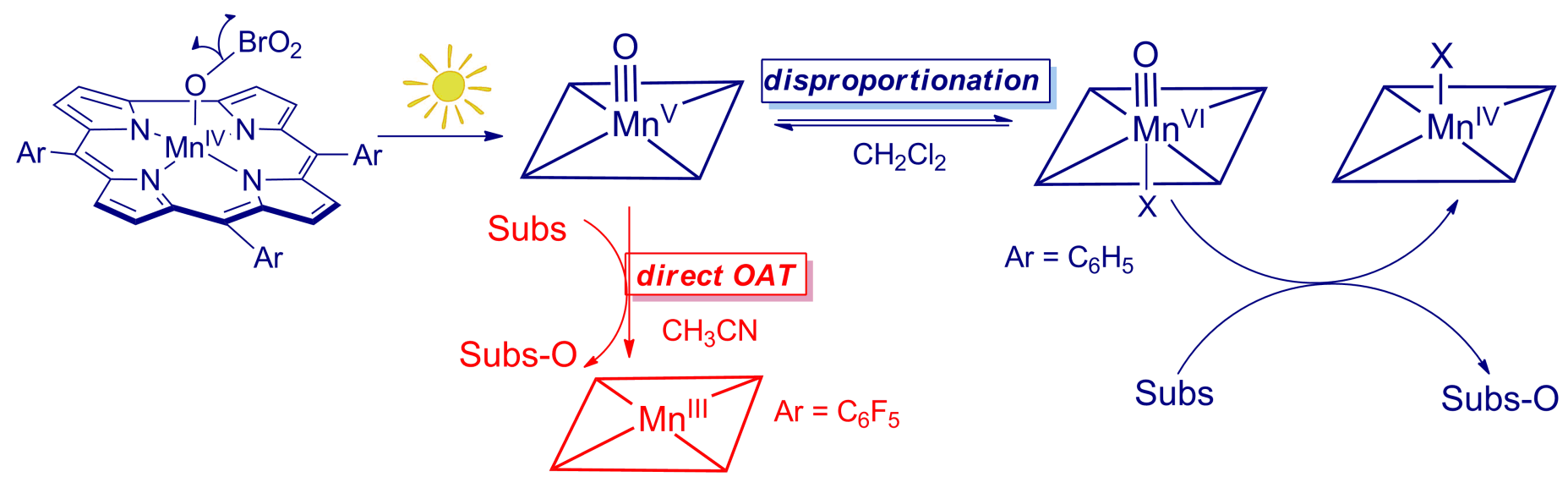




\title{
Visible light-induced formation of corrole-manganese(V)-oxo complexes: Observation of multiple oxidation pathways
}

\author{
Ka Wai Kwong, Ngo Fung Lee, Davis Ranburger, Jonathan Malone and Rui Zhang* \\ Department of Chemistry, Western Kentucky University, Bowling Green, KY 42101-1079, USA \\ * Corresponding author: Rui Zhang, Department of Chemistry, Western Kentucky University, \\ 1906 College Heights Blvd \#11079, Bowling Green, KY 42101-1079 \\ Phone:270-745-3803, Fax: 270-745-5361, e-mail: rui.zhang@wku.edu
}




\begin{abstract}
Two manganese(V)-oxo corroles $\left[\mathrm{Mn}^{\mathrm{V}}(\mathrm{Cor}) \mathrm{O}\right]$ that differ in their electronic environments were produced by visible light irradiation of highly photo-labile corrole-manganese(IV) bromates. The corrole ligands under study include 5,10,15-tris(pentafluorophenyl)corrole (TPFC), and 5,10,15triphenylcorrole (TPC). The kinetics of oxygen transfer atom (OAT) reactions with various organic reductants by these photo-generated $\mathrm{Mn}^{\mathrm{V}}$ (Cor)O were also studied in $\mathrm{CH}_{3} \mathrm{CN}$ and $\mathrm{CH}_{2} \mathrm{Cl}_{2}$ solutions. $\mathrm{Mn}^{\mathrm{V}}$ (Cor)O exhibits remarkable solvent and ligand effect on its reactivity and spectral behavior. In the more electron-deficient TPFC system and in the polar solvent $\mathrm{CH}_{3} \mathrm{CN}$, $\mathrm{Mn}^{\mathrm{V}}$ (Cor)O returned $\mathrm{Mn}^{\mathrm{III}}$ corrole in the end of oxidation reactions. However, in the less polar solvent $\mathrm{CH}_{2} \mathrm{Cl}_{2}$ or in the less electron-deficient TPC system, $\mathrm{Mn}^{\mathrm{IV}}$ product was formed instead. Furthermore, with the same substrates and in the same solvent, the order of reactivity of $\mathrm{Mn}^{\mathrm{V}}$ (Cor)O was TPC $>$ TPFC, which is inverted from that expected based on the electrondemand of corrole ligands. Our spectral and kinetic results in this study provide compelling evidence in favor of multiple oxidation pathways, where $\mathrm{Mn}^{\mathrm{V}}$ (Cor)O may serve as direct twoelectron oxidant or undergo a disproportionation reaction to form a manganese(VI)-oxo corrole as the true oxidant. The choice of pathways is strongly dependent on the nature of the solvent and the corrole ligand.
\end{abstract}

\title{
Key Words
}

Manganese(V)-oxo; corroles; visible light; oxidation; kinetics 


\section{Introduction}

High-valent transition metal-oxo intermediates are of fundamental importance because of their central roles as active oxidizing species in enzymatic and synthetic catalytic oxidations.[14] Many transition metal catalysts have been extensively studied as models to probe the sophisticated oxygen atom transfer (OAT) mechanism as well as to invent enzyme-like oxidation catalysts.[5-8] In many cases, however, the active metal-oxo transients are still puzzling due to their high reactivities and/or low concentrations. Moreover, a high valent metal-oxo species detected in a reaction might not be the true oxidant but a precursor to the true oxidant that is formed in small, undetectable amounts.[9] In this context, metallocorroles have garnered considerable interest in their catalytic properties because they are 19-membered analogues of metalloporphyrins, and have the capacity to access higher metal-oxo species.[10-13] Thus, a number of metallocorroles including metallocorralizines (corralizines $=m e s o-N$-substituted tetrazocorroles)[14-17] have been synthesized and explored in a wide variety of catalytic oxidations.[14, 18-20] For examples, (imido)manganese(V)[21, 22] and (nitrido)manganese(V/VI) corroles[23] are stable enough to be well characterized spectroscopically. In particular, the relatively stable manganese(V)-oxo corroles, abbreviated as $\mathrm{Mn}^{\mathrm{V}}$ (Cor)O, which can be produced either by chemical oxidation or laser flash photolysis (LFP) methods, serve as important mechanistic probes for OAT reactions.[24-26] Nevertheless, the factors controlling their OAT reactivity with organic substrates are not fully understood, deserving further exploration.[27] For example, a well characterized $\mathrm{Mn}^{\mathrm{V}}$-oxo corrole produced from ozone oxidation of the $\mathrm{Mn}^{\mathrm{III}}$ precursor shows no reactivity toward olefins at room temperature.[19] Similarly, the $\mathrm{Mn}^{\mathrm{V}}$-oxo complex containing the more electron-deficient corralizine ligand is even more inert.[14] Recent studies reported by Gross and co-workers have 
suggested that highly electron-demanding corroles-manganese(V)-oxo species directly transfers oxygen atom, while relatively less electron-demanding corroles-managese(V)-oxo complexes undergo disproportionation reaction to generate corrole-managnese(VI)-oxo as the active oxidant.[28] In addition, a study by Yu et al. who measured the pseudo-first order rate constants of a variety of $\mathrm{Mn}^{\mathrm{V}}$-oxo corroles reacting with alkenes in different solvents indicated that the oxygen atom transfer pathway of these metal-oxo species is solvent-dependent.[29]

Photochemical activation of transition metal complexes to produce reactive oxidants has been known for decades.[30, 31] Notably, the use of laser flash photolysis methods to generate a variety of high-valent transition metal-oxo species supported by porphyrin and corrole ligands have been well developed.[27, 32-36] With photochemical production of reactive metal-oxo transients, one has access to time scales that are much shorter than the fastest mixing experiments. In addition, the kinetics of oxidation reactions by photo-generated metal-oxo species are not convoluted with the rate constants for formation of the reactive transients by reaction of the excess sacrificial oxidant with the low-valent metal species.[35] As our ongoing efforts to explore photochemical approaches to access high-valent metal-oxo species, we have utilized photo-induced ligand cleavage reactions to produce trans-dioxoruthenium(VI) porphyrins $[37,38]$ as well as a putative ruthenium(V)-oxo species[39] that was also found in a photo-disproportionation of the bis-porphyrin-ruthenium(IV) $\mu$-oxo dimer.[40] Very recently, we communicated a photo-induced entry to iron(IV)-oxo porphyrin radical cations (compound I models) or iron(IV)-oxo porphyrin (compound II models) as controlled by the electronic nature of porphyrin ligands.[41] In the present work, we report a visible light irradiation of triarylcorrole-manganese(IV) bromate complexes to form manganese(V)-oxo corroles and direct kinetic studies of their OAT reactions with organic reductants. Our kinetic and spectral results 
illustrate that the photo-generated manganese(V)-oxo corroles may oxidize the substrate through different oxidation pathways, depending on the nature of corrole ligand and the solvent.

\section{Experimental}

\subsection{Materials}

All commercial reagents were of the best available purity and were used as supplied unless otherwise specified. HPLC grade acetonitrile (99.93\%) and methylene chloride were distilled over $\mathrm{P}_{2} \mathrm{O}_{5}$ prior to use. Iodosylbenzene ( $\mathrm{PhIO}$ ) was purchased from the TCI America Co. and was used as obtained. Tris(4-bromophenyl)ammoniumyl hexachloroantimonate was purchased from Sigma-Aldrich Co and used as such. All reactive substrates, including all alkenes, ethylbenzene, 4-methoxythioanisole, 4-methylthioanisole, 4-fluorothioanisole, 4chlorothioanisole, thioanisole, for mixing kinetic studies were passed through a dry column of active alumina (Grade I) before use. Free corrole ligands including $\mathrm{H}_{3} \mathrm{TPFC}$ [42] and $\mathrm{H}_{3} \mathrm{TPC}[43]$ and their manganese(III) neutral complexes $\mathrm{Mn}^{\mathrm{III}}(\mathrm{TPFC})$ (1a) and $\mathrm{Mn}^{\mathrm{III}}(\mathrm{TPC})$ (1) $)$ were prepared by literature methods and characterized by ${ }^{1} \mathrm{H}$ NMR, IR and UV-vis spectroscopies, matching those reported.[19] Treatment of manganese(III) species 1 with tris(4bromophenyl)ammoniumyl hexachloroantimonate gave known corrole-manganese(IV) chloride salts 2.[24] Compound 2 were further purified through recrystallization from $\mathrm{CH}_{2} \mathrm{Cl}_{2} /$ hexane followed by column chromatography on silica gel to remove traces of the amine by-product.

\subsection{General procedure for visible light formation of manganese(V)-oxo corroles}

Photo-labile compounds 3 were prepared in situ by stirring 2 with excess of $\mathrm{Ag}\left(\mathrm{BrO}_{3}\right)$ in anaerobic $\mathrm{CH}_{3} \mathrm{CN}$, and the formation of bromate products 3 was indicated by the change of $\mathrm{UV}$ vis absorption (Fig. 1). The resulting solutions 3 were used for photochemical studies 
immediately after preparation. (Caution! Bromate salts of metal complexes are potentially explosive and should be handled with care). When the solution of $\mathbf{3}$ with concentrations of $c a .2$ $\times 10^{-5} \mathrm{M}$ was irradiated with visible light at ambient temperature, the time-resolved formation of 4 was complete within 2 min as monitored by UV-visible spectroscopy. The same oxo species 4 were also produced by chemical oxidation of 1 with 5 -fold excess of $\mathrm{PhIO}$ or $\mathrm{PhI}(\mathrm{OAc})_{2}$ in $\mathrm{CH}_{3} \mathrm{CN}$.
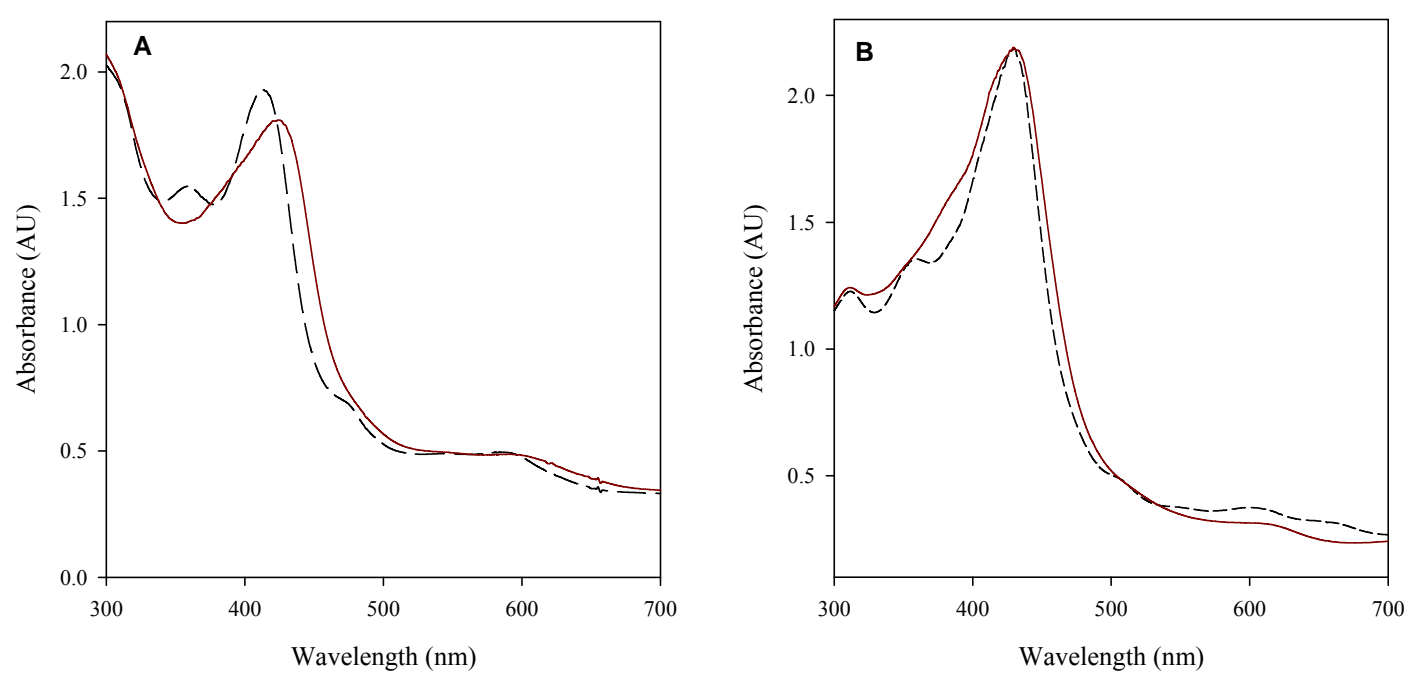

Fig. 1 Axial ligand exchange monitored by UV-visible spectroscopy: (A) $\mathrm{Mn}^{\mathrm{IV}}(\mathrm{TPFC}) \mathrm{Cl}$ (2a, dashed) and $\mathrm{Mn}^{\mathrm{IV}}$ (TPFC) $\left(\mathrm{BrO}_{3}\right.$ ) (3a, solid) in $\mathrm{CH}_{3} \mathrm{CN}$; (B) $\mathrm{Mn}^{\mathrm{IV}}$ (TPC)Cl (2b, dashed) and $\mathrm{Mn}^{\mathrm{IV}}(\mathrm{TPC})\left(\mathrm{BrO}_{3}\right)\left(3 \mathbf{b}\right.$, solid) in $\mathrm{CH}_{3} \mathrm{CN}$.

\subsection{Instrumentation and kinetic studies}

UV-vis spectra were recorded on an Agilent 8453 diode array spectrophotometer. ${ }^{1} \mathrm{H}$ NMR was performed on a JEOL ECA-500 MHz spectrometer at 298K with tetramethylsilane (TMS) as internal standard. Chemical shifts (ppm) are reported relative to TMS. IR spectra were obtained on a Bio-Rad FT-IR spectrometer. Kinetic measurements were performed on an Agilent 8453 diode array spectrophotometer interfaced with the Pro-K 2000 Rapid Mixing System (Applied Photophysics) by using standard 1.0-cm quartz cuvettes. Visible light was provided 
from a SOLA SE II light engine (Lumencor) configured with a liquid light guide. The output power can be adjusted from 6 to $120 \mathrm{~W}$.

Reactions of oxo-species 4 with excess organic substrate ( $>100$ equiv.) were conducted in a solution at $23 \pm 2{ }^{\circ} \mathrm{C}$. The approximate concentrations of the photo-generated 4 were estimated by assuming $100 \%$ conversion of manganese(IV) precursors in the photochemical reactions. The rates of the reactions which represent the rates of oxo group transfer from $\mathrm{Mn}^{\mathrm{V}}(\mathrm{Cor}) \mathrm{O}$ to substrate were monitored by the decay of the Soret absorption band of the oxo-species 4 . The kinetic traces at $\lambda$ max of Soret band displayed good pseudo-first-order behavior for at least four half-lives, and the data was solved to give pseudo-first-order observed rate constants, $k_{\text {obs. }}$ Plots of these values against the concentration of substrate were linear in all cases. The second-order rate constants for reactions of the oxo species with the organic substrates were solved according to Eq. (1), where $k_{0}$ is a background rate constant found in the absence of added substrate, $k_{\text {ox }}$ is the second-order rate constant for reaction with the substrate, and [Sub] is the concentration of substrate. All second-order rate constants are averages of 2-3 determinations consisting of 3 independent kinetic measurements. Errors in the rate constants were weighted and are at $2 \sigma$.

$$
k_{\mathrm{obs}}=k_{0}+k_{\mathrm{ox}}[\mathrm{Sub}]
$$

\section{$3 \quad$ Results and discussions}

\subsection{Visible light formation of corrole-manganese(V)-oxo complexes}

As shown in Scheme 1, two manganese(III) corroles (1) with different electronic environments were comparatively studied in this work. $\mathrm{Mn}^{\mathrm{III}}(\mathrm{TPFC})(\mathbf{1 a})$ and $\mathrm{Mn}^{\mathrm{III}}(\mathrm{TPC})(\mathbf{1 b})$ were both known and synthesized according to the reported procedure.[19, 27] As noticed in early reports, $[13,44]$ compound $1 \mathbf{a}$ is significantly stable in solutions; however, in $\mathrm{CH}_{2} \mathrm{Cl}_{2}$, the 
less electron-deficient $\mathbf{1 b}$ can be oxidized into $\mathrm{Mn}^{\mathrm{IV}}$ corrole. Oxidation of the neutral triarylcorrole-manganese(III) species 1 with tris(4-bromophenyl)ammoniumyl hexachloroantimonate gave the corrole-manganese(IV) chloride salts 2.[24] Facile exchange of the counterions in 2 with excess amount of $\mathrm{Ag}\left(\mathrm{BrO}_{3}\right)$ gave the corresponding bromate salts 3 , and its formation was indicated by the UV-vis spectra. These species 3 were highly photo-labile and attempts to isolate and spectroscopically characterize $\mathbf{3}$ more fully were not successful. Thus, they were prepared in situ and immediately used for photochemical reactions after preparation.

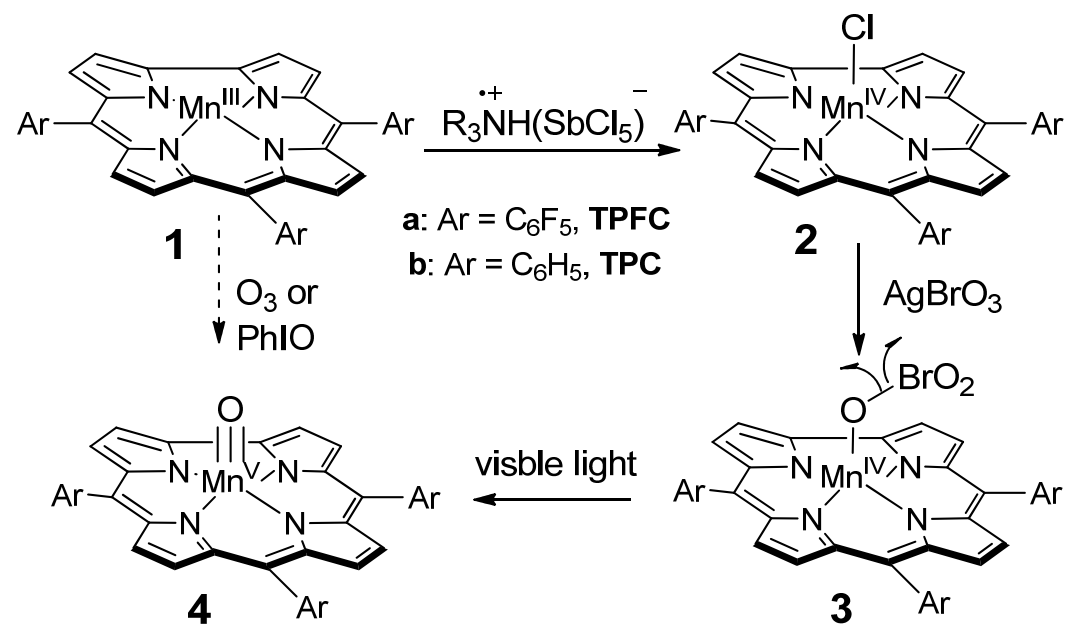

Scheme 1. Photochemical formation of corrole-manganese(V)-oxo complexes by visible light irradiation of manganese(IV) bromates

Irradiation of bromate complex 3 in anaerobic $\mathrm{CH}_{3} \mathrm{CN}$ with visible light from a SOLA engine (output power $60 \mathrm{~W}$ ) resulted in formation of corrole-manganese(V)-oxo species in two different systems, i.e. the electron-deficient 4a (Fig. 2A), and the non-electron-deficient $\mathbf{4 b}$ (Fig. 2B). By considering the electrophilic nature of the corrole-manganese(V)-oxo species, one can expect that the order of apparent stability is TPFC $<$ TPC. These time-resolved UV-vis absorption spectra show decay of photo-labile precursors (3) and growth of the oxo products (4) with clean isosbestic points at specific wavelengths labeled in Fig 2. As evident, the species 4a 
displayed split Soret bands that are distinct with a stronger blue-shifted band. In comparison to 4a, the absorption spectrum of the less electron-deficient $\mathbf{4 b}$ was similar in shape, but with a significantly weaker blue-shifted Soret band shown as a shoulder. Of note, the spectra of visible light-generated $\mathbf{4 a}$ and $\mathbf{4 b}$ matched those reported previously from ozone or $\mathrm{PhIO}$ oxidation of corresponding manganese(III) precursors 1 (see Fig S1 in the Supplementary Material).[19, 25] The formation of 4a by photochemical oxidation was also observed with a slower rate compared to that of $\mathbf{4 b}$. In the TPFC system, the oxidation of $\mathrm{Mn}^{\mathrm{IV}}$ species $\mathbf{3 a}$ from the highly electrondeficient corrole is apparently not favored in view of the expected high oxidation potential. On the contrary, the TPC system has the less electron-withdrawing aryl groups on the corrole ring; as thermodynamically favored; the $3 \mathbf{b}$ undergoes photo-oxidation to form $\mathbf{4 b}$ more readily.
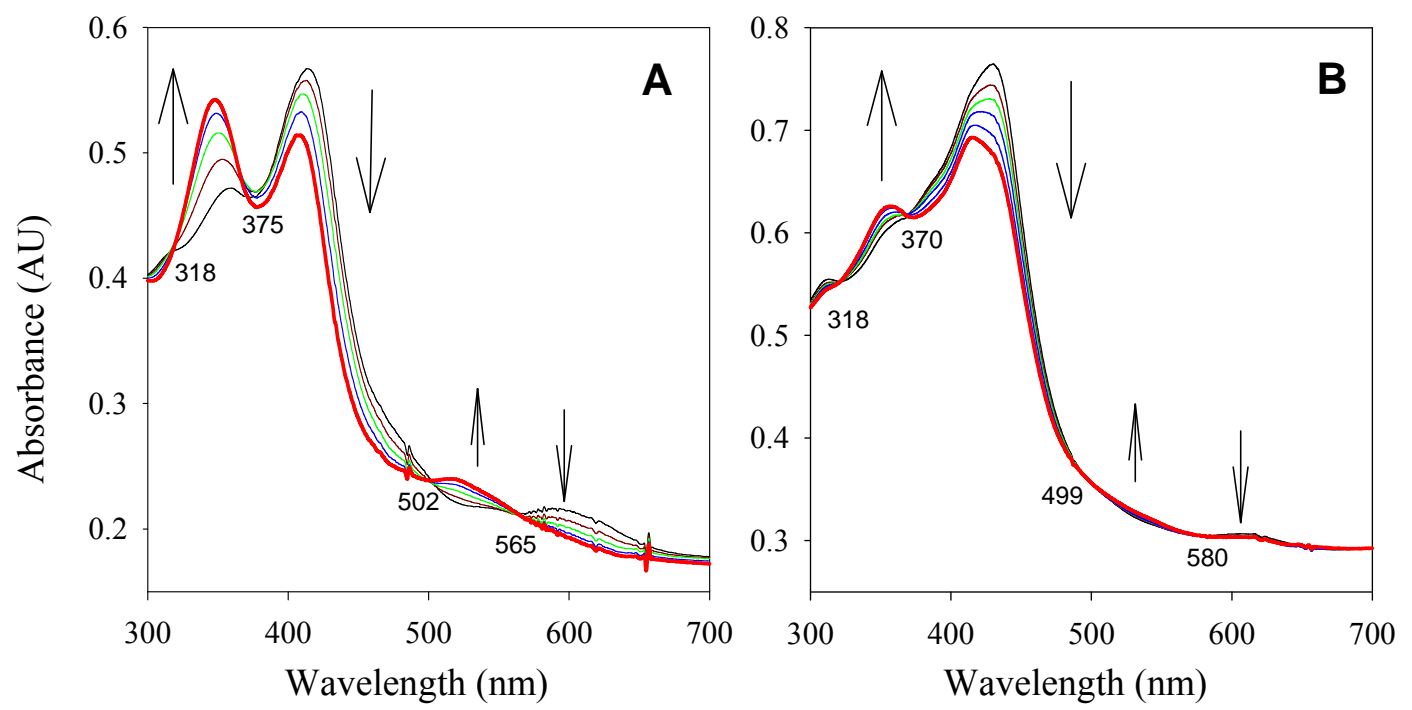

Fig.2 (A) Time-resolved formation spectra of $\mathbf{4 a}$ (red line) following irradiation of $3 \mathbf{a}\left(7.0 \times 10^{-6}\right.$ M) over $80 \mathrm{~s}$ with visible light in anaerobic $\mathrm{CH}_{3} \mathrm{CN}$ solution at $23^{\circ} \mathrm{C}$; (B) Spectra of $4 \mathbf{b}$ (red line) following irradiation of $3 \mathbf{b}\left(8.0 \times 10^{-6} \mathrm{M}\right)$ over $30 \mathrm{~s}$ with visible light.

Laser flash photolysis $(355 \mathrm{~nm})$ of corrole- $\mathrm{Mn}^{\mathrm{IV}}\left(\mathrm{ClO}_{3}\right)$ complexes gave $\mathrm{Mn}(\mathrm{V})$-oxo species by homolytic cleavage of an $\mathrm{O}-\mathrm{Cl}$ bond.[27] Photolysis of porphyrin- $\mathrm{Ru}^{\mathrm{IV}}\left(\mathrm{XO}_{3}\right)_{2}(\mathrm{X}=$ 
$\mathrm{Cl}$ and $\mathrm{Br}$ ) complexes was also reported to produce trans-dioxoruthenium(VI) species through analogous homolytic cleavage of the O-X bond.[37, 38] Clearly, visible light irradiation of bromates 3 represents the same homolysis manifold that results in one-electron photo-oxidation to afford corrole-manganese(V)-oxo species 4. Of note, we found that photochemical cleavages of the bromate complexes were considerably more efficient and faster than cleavages of chlorate complexes (see Fig S2 in the Supplementary Material). Control experiments showed that no species 4 was formed in the absence of light. As expected, using more intensive visible light (ca. $120 \mathrm{~W}$ ) resulted in about four times faster formation of $\mathbf{4 a}$ under same conditions. However, significant photo-degradation was found for $\mathbf{4 b}$ with high intensity light. The use of other solvents such as $\mathrm{CH}_{2} \mathrm{Cl}_{2}$ or EtOAc also gave similar results. However, no oxo formation was observed when $\mathrm{CH}_{3} \mathrm{OH}$ or THF was used. Presumably, the weakly binding bromate or chlorate counterions were displaced by these coordinating solvents.

\subsection{Kinetic and spectral studies}

Oxidation kinetics of photo-generated oxo species 4 with alkenes, activated hydrocarbon, and thioanisoles were investigated. In kinetic studies, solutions containing the oxo 4 were mixed with solutions containing large excesses of organic substrate, and pseudo-first-order rate constants for decay of the manganese(V)-oxo species were measured spectroscopically. Early report indicates the rates of reactions of corrole-manganese(V)-oxo species were dependent on its concentration.[27] Thus, we produced transients 4 in a similar concentration of approximate 2. $0 \times 10^{-5} \mathrm{M}$ for all kinetic studies. Fig. 3 shows the UV-vis spectra changes of 4a in the presence of organic substrate in different solvents. Fig 3A shows the clean conversion of $\mathbf{4 a}$ in $\mathrm{CH}_{3} \mathrm{CN}$ to regenerate the $\mathrm{Mn}^{\mathrm{III}}$ species with a distinct peak at $465 \mathrm{~nm}$. The decrease in 
absorbance at $348 \mathrm{~nm}$ corresponding to the decay of $4 \mathbf{a}$ was accompanied by an isosbestic growth at $465 \mathrm{~nm}$ characteristic formation of $\mathrm{Mn}^{\mathrm{III}}$ species (inset in Fig 3A). The traces were fit to single-exponential decay, as expected for reactions under pseudo-first-order conditions. When $\mathrm{CH}_{2} \mathrm{Cl}_{2}$ was used as the solvent instead of $\mathrm{CH}_{3} \mathrm{CN}$, Fig $3 \mathrm{~B}$ shows that the species $4 \mathrm{a}$ regenerated a $\mathrm{Mn}^{\mathrm{IV}}$ species which was characterized by its known $\lambda_{\max }$ at $430 \mathrm{~nm}$. This observation is in accord with previous LFP studies of $4 \mathbf{a}$, which was also found to give $\mathrm{Mn}^{\mathrm{IV}}$ species in $\mathrm{CH}_{2} \mathrm{Cl}_{2}$ solutions after the reaction.[27] In contrast, in both solvents reactions of the less electrondeficient $\mathbf{4 b}$ returned $\mathrm{Mn}^{\mathrm{IV}}$ species only and there was no evidence for accumulation of any $\mathrm{Mn}^{\mathrm{III}}$ (TPC) during the reaction(See Fig S3 in the Supplementary Material). It is worth to point out that the formation of reaction. $\mathrm{Mn}^{\mathrm{IV}}$ species in these reactions does not implicate one-electron reactions because the decay reactions are relatively slow.
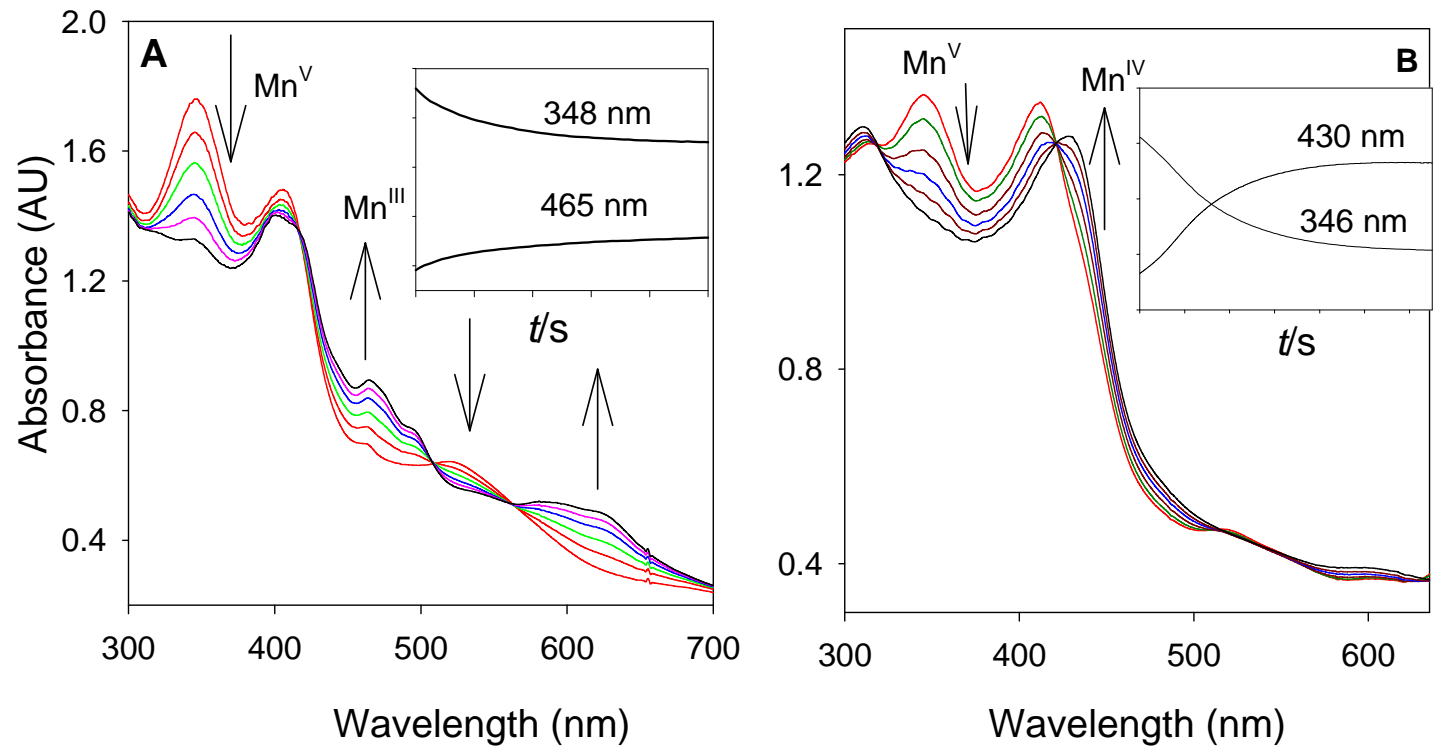

Fig. 3. Time-resolved spectra of 4 a reacting (A) in $\mathrm{CH}_{3} \mathrm{CN}$ with cyclohexene $(0.5 \mathrm{M})$ over 1000 s. Inset shows kinetic traces for decay of $4 \mathbf{a}(348 \mathrm{~nm})$ and formation of $\mathrm{Mn}^{\mathrm{III}}$ (465 nm). (B) $\mathrm{In} \mathrm{CH}_{2} \mathrm{Cl}_{2}$ with cyclohexene $(0.5 \mathrm{M})$ over $300 \mathrm{~s}$. Inset shows kinetic traces for decay of $4 \mathrm{a}(346 \mathrm{~nm})$ and formation of $\mathrm{Mn}^{\mathrm{IV}}(430 \mathrm{~nm})$. 
Although the decay reactions of species $\mathbf{4}$ were complex in different solvents and corrole systems, apparent pseudo-first-order decay rate constants for $\mathbf{4}$ increased linearly as a function of substrate concentration (Fig. 4), thus permitting calculation of apparent second-order rate constants $\left(k_{\mathrm{ox}}\right)$ for various substrates (Table 1$)$. The trend of the $k_{\mathrm{ox}}$ values in Table 1 clearly parallels the substrate reactivity; for examples, organic sulfides are about 3 or 4 orders of magnitude more reactive than alkenes or ethylbenzene with the same oxo species. Of note, the $k_{\text {ox }}$ values for cyclohexene are in good agreement with the values for oxidant 4a produced from the chemical oxidation method. For the para-substituted thioanisoles (Y-thioanisoles; $\mathrm{Y}=4$ $\mathrm{MeO}$, 4-Me, 4-F, and 4-Cl), we observed a significant substituent dependence on the secondorder rate constants, as reflected in the Hammett plot shown Fig. 4B. A linear correlation $(\mathrm{R}=0.99)$ of $\log k_{\mathrm{rel}}\left[k_{\mathrm{rel}}=k(\right.$ para $-\mathrm{Y}$-thioanisole $) / k($ thioanisole $\left.)\right]$ versus Hammett $\sigma^{+}$substituent constant[45] gave the slope $\left(\rho^{+}\right)$of the plot as $-1.34 \pm 0.18$, which reflects the degree of positive charge development on the styrene in the transition states for the oxo transfer reactions. Similar values were also found with species $4 \mathbf{a}$ generated by the chemical method in different solvent (EtOAc).[28] The Hammett correlation results strongly suggest that the observed manganese(V)oxo species is likely to be the active oxidant which transfers an oxygen atom to thioanisoles through an electrophilic mechanism. 

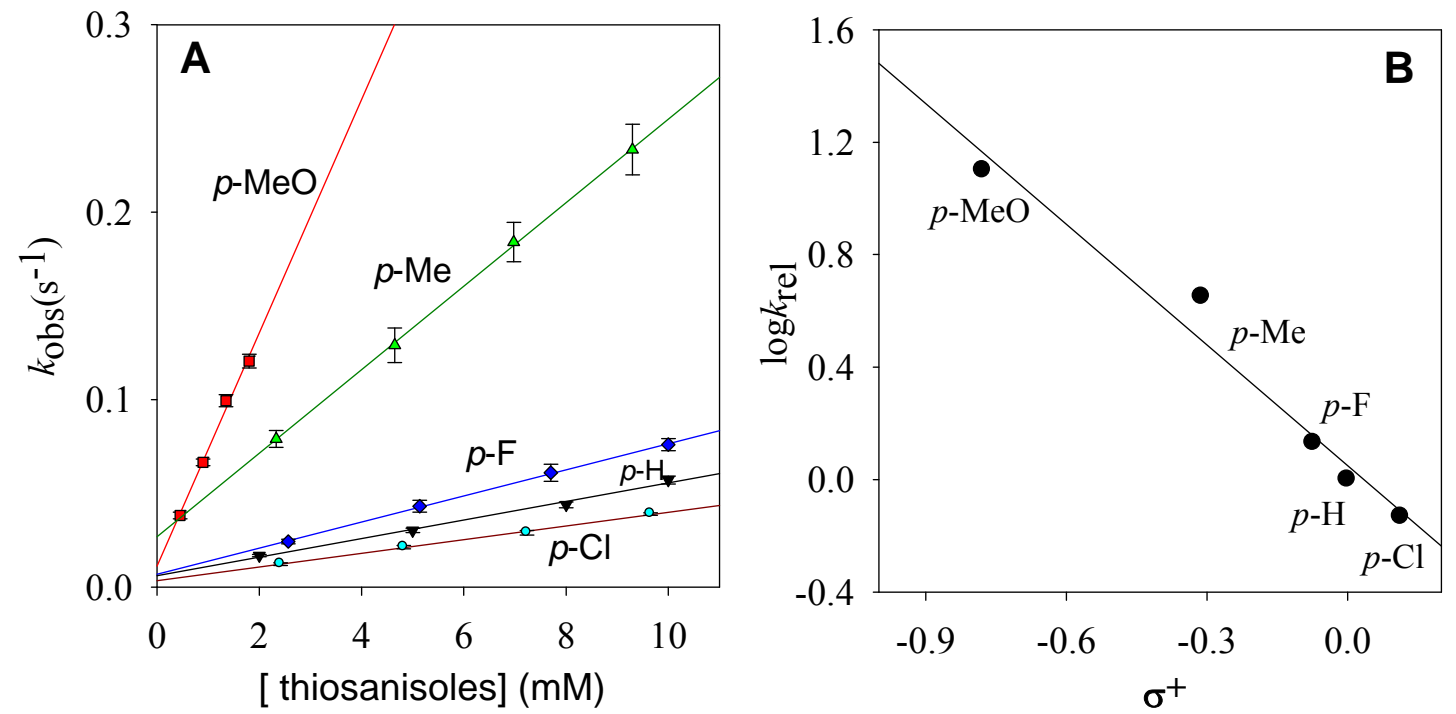

Fig. 4. (A) Plots of the observed rate constants ( $\left.k_{\mathrm{obs}}\right)$ versus the concentration of para-substituted thioanisoles; (B) Hammett plot for oxidations of para-substituted thioanisoles with 4a in $\mathrm{CH}_{3} \mathrm{CN}$.

Table 1. Apparent second-order rate constants $\left(k_{\mathrm{ox}}\right)$ for reactions of photo-generated corrolemanganese(V)-oxo species ${ }^{a}$

\begin{tabular}{cccc}
\hline Oxo & Substrate & \multicolumn{2}{c}{$k_{\text {ox }}\left(\mathrm{M}^{-1} \mathrm{~s}^{-1}\right)$} \\
\cline { 2 - 4 } & & $\mathrm{CH}_{3} \mathrm{CN}$ & $\mathrm{CH}_{2} \mathrm{Cl}_{2}$ \\
\hline 4a & cyclohexene & $(3.4 \pm 0.2) \times 10^{-3}$ & $(1.6 \pm 0.2) \times 10^{-2}$ \\
& cyclohexene $^{b}$ & $(3.9 \pm 0.4) \times 10^{-3}$ & $(1.5 \pm 0.1) \times 10^{-2}$ \\
& cis-cyclooctene & $(2.9 \pm 0.2) \times 10^{-3}$ & $(11.0 \pm 0.9) \times 10^{-3}$ \\
& PhEt & $(1.4 \pm 0.1) \times 10^{-4}$ & \\
styrene & $(3.0 \pm 0.1) \times 10^{-3}$ & \\
PhSMe & $4.9 \pm 0.4$ & \\
& -MeO-PhSMe & $62.0 \pm 0.7$ & \\
$p$-Me-PhSMe & $22.0 \pm 0.6$ & \\
$p$-F-PhSMe & $6.7 \pm 0.5$ & \\
& $p$-Cl-PhSMe & $3.6 \pm 0.3$ & \\
4b & cyclohexene & $(10.0 \pm 1.0) \times 10^{-2}$ & \\
& cis-cyclooctene & $(5.0 \pm 06) \times 10^{-2}$ & \\
& PhEt & $(2.1 \pm 0.3) \times 10^{-3}$ & \\
& PhSMe & $6.0 \pm 0.8$ & \\
& $p$-MeO-PhSMe & $85.5 \pm 2.4$ & \\
$p$-F-PhSMe & $24.8 \pm 1.5$ & \\
\hline
\end{tabular}


${ }^{a}$ In $\mathrm{CH}_{3} \mathrm{CN}$ or $\mathrm{CH}_{2} \mathrm{Cl}_{2}$ with a concentration of $2.0 \times 10^{-5} \mathrm{M}$ at $23 \pm 2{ }^{\circ} \mathrm{C}$. The values are average of 3 runs with $2 \sigma$ standard deviation;

${ }^{b}$ From 4a generated by chemical oxidation of 1a.[25]

\subsection{Mechanistic consideration for multiple oxidation pathways}

One of the noteworthy aspects of the manganese(V)-oxo kinetics is the fact that a remarkable solvent effect on the reactivity and spectral behavior of $\mathbf{4 a}$ was observed. In addition to decaying back to $\mathrm{Mn}^{\mathrm{IV}}$ corrole in $\mathrm{CH}_{2} \mathrm{Cl}_{2}$ solution, 4a exhibited higher reactivity in $\mathrm{CH}_{2} \mathrm{Cl}_{2}$ than that in $\mathrm{CH}_{3} \mathrm{CN}$ with same substrates. Owing to the electrophilic nature of high-valent metaloxo species, one typically observes that more electron-withdrawing ligands give more reactive metal-oxo derivatives. For the two corrole systems studied here, however, the reactivity order is inverted with the system of less electron demand, i.e. the triphenylcorrole complex $\mathbf{4 b}$ apparently reacting faster with any given substrate than the more electron-deficient $4 a$. These kinetic results strongly support the previously proposed mechanistic model involving disproportionation of 4 to give $\mathrm{Mn}^{\mathrm{IV}}$ corrole and a more reactive corrole-manganese(VI)-oxo cationic species (5) as the predominant oxidants in these systems.[19, 27, 28] Importantly, the report of a wellcharacterized corrole-manganese(VI)-nitrido species suggests that such high oxidation state manganese species are accessible.[23] In practice, the concentration of 5 might be too small to permit observation, and the major species observed spectroscopically is still $\mathbf{4}$. If complexes $\mathbf{5}$ are the actual oxidants, then the equilibrium reactions for formation of these species should be more favorable for the ligand that has the less electron demand. Accordingly, the observed kinetics could reflect the populations of species 5 controlled by the disproportionation equilibrium constant which should be larger for the TPC ligand.[27] The mechanistic model is similar to that proposed for reactions of neutral porphyrin-manganese(IV)-oxo species, where 
the actual oxidants in the systems apparently are cationic porphyrin-manganese(V)-oxo species formed in disproportionation equilibria.[9]

In view of the above significant decaying spectra and the rate constants of photogenerated species $\mathbf{4}$, we propose that the oxidation of organic substrates by corrolemanganese(V)-oxo corroles may proceed via two different pathways as shown in Scheme 2. In the more electron-deficient corrole system and in the polar solvent $\mathrm{CH}_{3} \mathrm{CN}$, the active oxidizing specie is $\mathrm{Mn}^{\mathrm{V}}$-oxo corrole, and the dominant pathway is the electrophilic reaction between $\mathrm{Mn}^{\mathrm{V}}$ oxo corrole and substrate (Scheme 2, path a). In this situation, $\mathrm{Mn}^{\mathrm{III}}$ corrole was observed in the end of reaction. When the less polar solvent $\mathrm{CH}_{2} \mathrm{Cl}_{2}$ and/or the less electron-deficient system were involved, the direct OAT process becomes progressively less favorable and the disproportionation reaction of species 4 (path b) to form $\mathrm{Mn}^{\mathrm{VI}}$-oxo (5) as the active oxidant gains dominance. As outlined in Scheme 2, photo-disproportionation of $\mathbf{4}$ gives the highly reactive manganese(VI)-oxo 5 in addition to one molecule of a $\mathrm{Mn}^{\mathrm{IV}}$ product; oxidation of an organic reductant by 5 gives a second molecule of $\mathrm{Mn}^{\mathrm{IV}}$ product. During the course of the reaction, the proposed $\mathrm{Mn}^{\mathrm{VI}}$-oxo 5 was not accumulated to be detected because it reacts much faster than it is formed. This mechanism provided a rationalization for the inverted reactivity patterns for $\mathbf{4}$ as well as the final $\mathrm{Mn}^{\mathrm{IV}}$ product formation observed during reactions. It is worth noting that remarkable solvent and ligand effects on the participation of multiple active oxidants were previously known in heme- and nonheme-manganese(III) catalyzed oxidation reactions.[46, 47] 

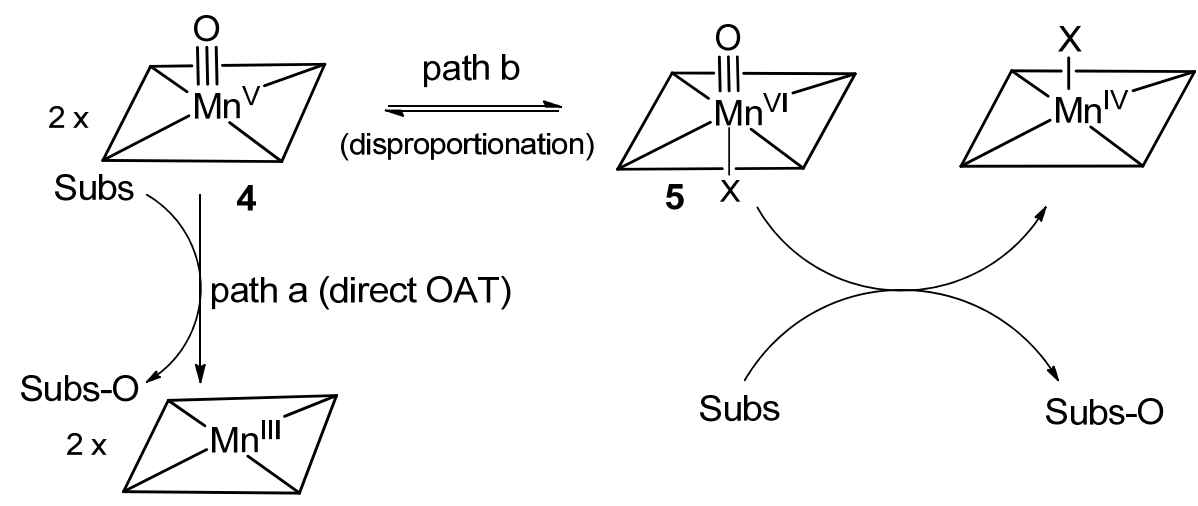

Scheme 2. Two oxidation pathways of corrole-manganese(V)-oxo species controlled by the nature of ligands and solvents. The parallelogram represents a corrole structure and subs stands for organic substrates.

\section{Conclusions}

In conclusion, we report here a new photochemical entry to produce and study high-valent corrole-manganese(V)-oxo derivatives by visible light irradiation of the corresponding manganese(IV) bromate complexes. The photochemistry is ascribed to the homolytic cleavage of the $\mathrm{O}-\mathrm{Br}$ bond that results in an one-electron oxidation to generate the manganese( $\mathrm{V})$-oxo species. We have observed the remarkable effect of the nature of the corrole ligand and the solvent on oxidation pathways of these high-valent corrole-metal-oxo intermediates. Our kinetic and spectral findings in this work provide compelling evidence to support multiple oxidation pathways of biomimetic corrole- $\mathrm{Mn}^{\mathrm{V}}$-oxo species. A thorough investigation of solvent effects on the reactivities of various manganese $(\mathrm{V})$-oxo corroles derived from different electron-rich and electron-poor substituents are currently underway in our laboratory. 
Table of Abbreviations

\begin{tabular}{|l|l|}
\hline Cor & Corrole \\
\hline TPFC & $5,10,15$ - tripentafluorophenylcorrole trianion \\
\hline TPC & $5,10,15$ - triphenylcorrole trianion \\
\hline PhIO & Iodosylbenzene \\
\hline LFP & Laser flash photolysis \\
\hline OAT & Oxygen atom transfer \\
\hline
\end{tabular}

\section{Acknowledgments}

We greatly acknowledge the National Science Foundation (CHE 1464886) and Kentucky NSF EPSCoR program (REG 2015) for support of this research. K. W. Kwong is grateful to the Graduate School of WKU for a Graduate Student Research Fellowship (GSRF). D. Ranburger and J. Malone are thankful to the WKU Office of Research for awarding internal FUSE grants.

Fig. 1 Axial ligand exchange monitored by UV-visible spectroscopy: (A) $\mathrm{Mn}^{\mathrm{IV}}$ (TPFC)Cl (2a, dashed) and $\mathrm{Mn}^{\mathrm{IV}}$ (TPFC)( $\left.\mathrm{BrO}_{3}\right)$ (3a, solid) in $\mathrm{CH}_{3} \mathrm{CN}$; (B) $\mathrm{Mn}^{\mathrm{IV}}$ (TPC)Cl (2b, dashed) and $\mathrm{Mn}^{\mathrm{IV}}(\mathrm{TPC})\left(\mathrm{BrO}_{3}\right)\left(3 \mathbf{b}\right.$, solid) in $\mathrm{CH}_{3} \mathrm{CN}$.

Fig.2 (A) Time-resolved formation spectra of $\mathbf{4 a}$ (red line) following irradiation of $3 \mathbf{a}\left(7.0 \times 10^{-6}\right.$ M) over $80 \mathrm{~s}$ with visible light in anaerobic $\mathrm{CH}_{3} \mathrm{CN}$ solution at $23^{\circ} \mathrm{C}$; (B) Spectra of $4 \mathbf{b}$ (red line) following irradiation of $3 \mathbf{b}\left(8.0 \times 10^{-6} \mathrm{M}\right)$ over $30 \mathrm{~s}$ with visible light.

Fig. 3. Time-resolved spectra of 4a reacting (A) in $\mathrm{CH}_{3} \mathrm{CN}$ with cyclohexene $(0.5 \mathrm{M})$ over $1000 \mathrm{~s}$. Inset shows kinetic traces for decay of $4 \mathrm{a}(348 \mathrm{~nm})$ and formation of $\mathrm{Mn}^{\mathrm{III}}(465 \mathrm{~nm})$. (B) $\mathrm{In} \mathrm{CH}_{2} \mathrm{Cl}_{2}$ with cyclohexene $(0.5 \mathrm{M})$ over $300 \mathrm{~s}$. Inset shows kinetic traces for decay of $4 \mathbf{a}(346 \mathrm{~nm})$ and formation of $\mathrm{Mn}^{\mathrm{IV}}(430 \mathrm{~nm})$. 
Fig. 4. (A) Plots of the observed rate constants $\left(k_{\mathrm{obs}}\right)$ versus the concentration of para-substituted thioanisoles; (B) Hammett plot for oxidations of para-substituted thioanisoles with 4a in $\mathrm{CH}_{3} \mathrm{CN}$.

Scheme 1. Photochemical formation of corrole-manganese(V)-oxo complexes by visible light irradiation of manganese(IV) bromates

Scheme 2. Two oxidation pathways of corrole-manganese(V)-oxo species controlled by the nature of ligands and solvent. The parallelogram represents a corrole structure and subs stands for organic substrates.

Table 1. Apparent second-order rate constants $\left(k_{\mathrm{ox}}\right)$ for reactions of photo-generated corrolemanganese(V)-oxo species

\section{References}

[1] B. Meunier (Ed.), Metal-Oxo and Metal-Peroxo Species in Catalytic Oxidations, Springer-Verlag, Berlin, 2000.

[2] A.R. McDonald, L. Que, Coord. Chem. Rev. 257 (2013) 414-428.

[3] S.P. de Visser, W. Nam, in: K.M. Kadish, K.M. Smith, R. Guilard (Eds.), Handbook of Porphyrin Science, World Scientific Publishing, Singapore, 2010, pp. 85-139.

[4] P.R. Ortiz de Montellano (Ed.), Cytochrome P450 Structure, Mechanism, and Biochemistry, 3rd ed., Kluwer Academic/Plenum, New York, 2005.

[5] B. Meunier, Chem. Rev. 92 (1992) 1411-1456.

[6] R.A. Sheldon (Ed.), Metalloprophyrins In Catalytic Oxidations, Marcel Dekker, New York, 1994.

[7] I.G. Denisov, T.M. Makris, S.G. Sligar, I. Schlichting, Chem. Rev. 105 (2005) 22532277. 
[8] C.-M. Che, J.-S. Huang, Chem. Commun. (2009) 3996-4015.

[9] R. Zhang, J.H. Horner, M. Newcomb, J. Am. Chem. Soc. 127 (2005) 6573-6582.

[10] Z. Gross, H.B. Gray, Adv. Syn. Catal. 346 (2004) 165-170.

[11] I. Aviv, Z. Gross, Chem. Commun. (2007) 1987-1999.

[12] D.P. Goldberg, Acc. Chem. Res. 40 (2007) 626-634.

[13] H.-Y. Liu, M.H.R. Mahmood, S.-X. Qiuc, C.K. Chang, Coord. Chem. Rev. 257 (2013) 1306-1333.

[14] B.S. Mandimutsira, B. Ramdhanie, R.C. Todd, H.L. Wang, A.A. Zareba, R.S. Czernuszewicz, D.P. Goldberg, J. Am. Chem. Soc. 124 (2002) 15170-15171.

[15] W.D. Kerber, D.P. Goldberg, J. Inorg. Biochem. 100 (2006) 838-857.

[16] P. Leeladee, D.P. Goldberg, Inorg. Chem. 49 (2010) 3083-3085.

[17] K.A. Prokop, D.P. Goldberg, J. Am. Chem. Soc. 134 (2012) 8014-8017.

[18] A.E. Meier-Callahan, H.B. Gray, Z. Gross, Inorg. Chem. 39 (2000) 3605-3607.

[19] Z. Gross, G. Golubkov, L. Simkhovich, Angew. Chem. Int. Ed. Engl. 39 (2000) 40454047.

[20] H.-Y. Liu, F. Yam, Y.-T. Xie, X.-Y. Li, C.K. Chang, J. Am. Chem. Soc. 131 (2009) 12890-12891.

[21] R.A. Eikey, S.I. Khan, M.M. Abu-Omar, Angew. Chem., Int. Ed. 41 (2002) 3592-3295.

[22] N.Y. Edwards, R.A. Eikey, M.I. Loring, M.M. Abu-Omar, Inorg. Chem. 44 (2005) 37003708.

[23] G. Golubkov, Z. Gross, J. Am. Chem. Soc. 127 (2005) 3258-3259.

[24] G. Golubkov, J. Bendix, H.B. Gray, A. Mahammed, I. Goldberg, A.J. DiBilio, Z. Gross, Angew. Chem., Int. Ed. 40 (2001) 2132-2134. 
[25] H.Y. Liu, T.S. Lai, L.L. Yeung, C.K. Chang, Org. Lett. 5 (2003) 617-620.

[26] C.J. Bougher, S. Liu, S.D. Hicks, M.M. Abu-Omar, J. Am. Chem. Soc. 137 (2015) $14481-14487$.

[27] R. Zhang, D.N. Harischandra, M. Newcomb, Chem. Eur. J. 11 (2005) 5713-5720.

[28] A. Kumar, I. Goldberg, M. Botoshansky, Y. Buchman, G. Z., J. Am. Chem. Soc. 132 (2010) 15233-15245.

[29] L. Yu, Q. Wang, L. Dai, W.Y. Li, R. Chen, M. Mahmooda, H.Y. Liu, C.K. Chang, Chin. Chem. Lett. 24 (2013) 447-449.

[30] K.S. Suslick, R.A. Watson, New J. Chem. 16 (1992) 633-642.

[31] H. Hennig, Coord. Chem. Rev. 182 (1999) 101-123.

[32] R. Zhang, M. Newcomb, J. Am. Chem. Soc. 125 (2003) 12418-12419.

[33] D.N. Harischandra, R. Zhang, M. Newcomb, J. Am. Chem. Soc. 127 (2005) 1377613777.

[34] Z. Pan, R. Zhang, L.W.M. Fung, M. Newcomb, Inorg. Chem. 46 (2007) 1517-1519.

[35] R. Zhang, M. Newcomb, Acc.Chem. Res. 41 (2008) 468-477.

[36] Z. Pan, Q. Wang, X. Sheng, J.H. Horner, M. Newcomb, J. Am. Chem. Soc. 131 (2009) 2621-2628.

[37] Y. Huang, E. Vanover, R. Zhang, Chem. Commun. 46 (2010) 3776-3778.

[38] R. Zhang, Y. Huang, C. Abebrese, H. Thompson, E. Vanover, C. Webb, Inorg. Chim. Acta 372 (2011) 152-157.

[39] R. Zhang, E. Vanover, W.-L. Luo, M. Newcomb, Dalton Transactions 43 (2014) 87498756.

[40] E. Vanover, Y. Huang, L. Xu, M. Newcomb, R. Zhang, Org. Lett. 12 (2010) 2246-2249. 
[41] T.S. Chen, N. Asiri, K.K. Kwong, J. Malone, R. Zhang, Chem. Commun. 51 (2015) 9949-9952.

[42] Z. Gross, N. Galili, L. Simkhovich, I. Saltsman, M. Botoshansky, D. Blaeser, R. Boese, I. Goldberg, Org. Lett. 1 (1999) 599-602.

[43] B. Koszarna, D.T. Gryko, J. Org. Chem. 71 (2006) 3707-3717.

[44] Q. Wang, Y. Zhang, L. Yu, H. Yang, M. Mahmood, H.Y. Liu, J. Porphyrins

Phthalocyanines 18 (2014) 316-325.

[45] C. Hansch, A. Leo, R.W. Taft, Chem. Rev. 91 (1991) 165-195.

[46] Y.J. Song, H. Sun, H.M. Park, S.H. Kim, H.G. Goo, G.H. Eom, J.H. Lee, M.S. Lah, Y. Kim, S.-J. Kim, J.E. Lee, H.-I. Lee, C. Kim, Chem. Eur. J. 17 (2011) 7336-7344.

[47] M.Y. Hyun, Y.D. Jo, J.H. Lee, H.G. Lee, H.M. Park, I.H. Hwang, K.B. Kim, S.J. Lee, C. Kim, Chem. Eur. J. 19 (2013) 1810-1818. 